\title{
CONFERENCE OF NAVAL AND MILITARY HYGIENISTS.
}

\section{ADDRESS}

$\mathrm{BY}$

INS.-GEN. J. D. MACDONALD, R.N., F.R.S.

PRESIDENI OF THE CONFERENCE.

Having been requested by the Council of "The Sanitary Institute" to act as President of the Conference of Naval and Military Hygienists, it devolves upon me to open the business of the Conference with an address on Hygienic matters. But, as the subject is wide and far reaching I must be satisfied with the consideration of some few important particulars, which I am led to hope will be of interest to those who may not have had precisely the same opportunities of investignting them. I always feel both proud and thankful to lave been the friend and colleague of the late Professor Parkes at Netley, up to the date of his lamented death. One of the last things I submitted to him was a paper on the microscopic organisms detected in samples of ground air obtained on the spot. $U_{p}$ to that time the chemical constitution of the ground air had been investigated to a certain extent, particularly the increase of carbonic: acid in proportion to the depth, but, no results of microscopical examination had been recorded. He gave me the sage advice not to make any public statement of the matter until $\bar{I}$ had amply supported my position by further experiment and proof. In passing I might say that the additional proof has been obtained, opening up quite a new field of research.

The ground air, like the ground water, is a subject of great importance, and has very largely claimed the attention of lyggienists during the last few years. It is subject to its currents, storms, and calms, like the atmosphere above it, and though always more or less impure, it may be poisoned or infected with the products of specific organisms, as well as with the organisms themselves. Passing from this to the question 
of drinking-water, I desire especially to call your attention to a persistent cause of its contamination in the play of the vital functions of the Protophyta and Protoza. But, for the more satisfactory comprehension of this interesting subject, it will be necessary to premise some general principles and then show their application in the particular cases adcluced. In the first place, we know that gases, liquids, and solids tend, or may be made to intermix homogeneously by the exercise of attractive and cohesive forces, which are ever restless until an equilibrium is established. Simple as this statement is, it forms the basis of at least three important laws, viz.:-(1st) The diffusion of gases; (2nd) the osmosis of fluids; and (3rd) the dialysis of crystalloidal substances, the same affinities being exercised with or without the interposition of a medium. The first law manifests itself most strikingly, in the preservation of the same formula of composition in the atmosphere all over the globe. The second is perhaps best seen in the circulation of the sap of plants, and the third in the processes of deposition, and absorption in animals. The three great laws are each brought into activity under special conditions, and pressed into the service of Nature to fulfil by plyysical agency certain offices in the organic world, which were formerly supposed to be of a purely vital character.

Time would fail us in the attempt to give even a very cursory sketch of the numerous purposes subserved by these laws, but the subject of Osmosis, and of Dialysis in particular, as applied to the physiology of nutrition in the lower orders of plants and animals, may profitably engage our attention for a short time.

1. The materials of which organised bodies are composed are capable of either crystallization or are non-crystallizable, named respectively crystalloidal and colloidal substances, by Dr. Richardson, whose simple and intelligent view of the subject will answer our purpose admirably.

2. Crystalloidal substances are usually found in the fluid state, scarcely ever assuming the crystalline form, except under morbitic conditions, and they will exhibit this tendency in the inverse ratio of their solubility. Thus, we find crystals of cholesterine in atheromatous deposits, carbonate of lime in the coats of the minute cerebral arteries and lithate of soda in gouty concretions, which owe their segregation and subsequent persistency to the absorption of the water with which they were originally thrown out from the capillary vessels. Besides the Raphides in plants, crystals also as snch are to be found in some animal bodies, as in the Thalassieollida for example.

3. Colloidal substances, on the other hand, are found either in the liquid or plastic state for the growth and repair of the tissues, Albumen, Fibrine and Gelatine in the muscles, 
Albumen particularly in the nerves and brain, and Gelatine in connective tissue, ligament and bone.

4. In the vital Huid, blood, both crystalloidal and colloidal bodies are homogeneously blended together in watery solution. The latter components take up water from the former and so continually yield it up again by transpiration, that a regulated supply of water is necessary to keep up this cycle of actions and preserve the fluidity of the circulating mass.

5. The late Professor Graham first demonstrated that crystalloidal substances will pass through a colloidal membrane floating on water and diffuse themselves through the latter, while colloidal substances also present are left behind on the dialysing membrane. In this way the poisonous alkaloids are usually isolated from the other contents of the stomach, and identified by their appropriate tests in medico-legal investigations. Now the walls of the blood-vessels are literally dialysing membranes, and the facts to which we have alluded shed much light on the physiology of absorption, deposition, nutrition, and secretion. It will be part of my purpose to-day to show that the extraordinary pseudo-volitional movements of certain minute algals, more particularly Bacterians, Oscillatorians, Diatoms, and Desmids, are due to the play of the same forces. In my work on the "Microscopical Examination of Drinking Water," I have endeavoured to show that a similar explanation will apply even to the pseudopodial extensions of the Rlizopoda and the gliding movements of the Gregaraino, which are destitute of cilia.

The law of intermittency observable in the phenomena connected with assimilation and decay is most interesting, and quite in the same category as that which we notice in the circulatory, respiratory and cligestive functions of animals in general. The first appearance of the germinal vesicle and spot in the ovum, its final dissolution, and the substitution of two new cells in its stead, afford us the earliest evidence of that intermittency of action or interchange of building up and breaking down which is to all living things an essential condition of existence. In further illustration of the principle I am advocating, I wish to refer you to the anatomy of the lower division of animals. In the naked eyed medusa for example, four great vessels radiate from the central somatic cavity to the corresponding generative organs nearer the margin of the dise, to and from which parts the current of blood intermittingly flows. Thus, the materials of growth and development are conveyed to the ovaries one moment, while the products of decay are carried back by the same vessels the moment following. The circulation in the Brachiopod (e.g., Lingula) is even more remarkable, for, 
although it also is effected by ciliary motion as in the Polyzoa, the out-going and returning currents course along the opposite sides of the same rascular channels.

The first unequivocal heart occurring in that well-marked series of beings which culminates in the true Mollusca, is found in the Tunicata. But here, as the circulatory system is in effect single, without any valvular mechanism, the whole round of the circulation sweeps alternately in opposite clirections. Thus, the vessels conveying blood to a particular part one moment carry it back the next, when the course of the circulation is reversed. It is obvious therefore, that each vessel must play the part of artery and vein successively, affording another good instance of intermittency in those functions connected with the supply of new, and the removing of old material.

A perfect heart, with a receptive and a propulsive chamber, so arranged as to determine an irreversible path to the circulation, and the persistent distinctiveness of arteries and veins, distinguishes the Mollusca proper from the Molluscoida and Colenterata, to whose blood vascular systen allusion has been made. Organic cells, whether they appertain to plant or animal, are nourished in the same way, practically speaking, and while the singular movements exhibited by Bacteria and Diatoms are clearly due to invisible Dialytic or Osmotic currents, their obvious remittency bears out the views expressed in the foregoing remarks.

For many years after the publication of the great work of Ehrenberg on the INFUSORIA, while numerous unequivocal plants were eliminated from that omnium gatherum of organic forms, the Diatoms and Desmids, perhaps solely on account of their apparently volitional movements, remained in a doubtf ul position. They were constantly adduced in evidence of that neutral ground in which the animal and vegetable kingdoms were supposed to blend with each other or take a common origin. Indeed, the same may be said of the Bacteria; even the name of the putrefactive Bacterium termo was chosen to express the ultimate limit of animal life. At the present time, however, no doubt on the one hand can be entertained as to the vegetable nature of these forms or the absence of true volition in their movements on the other. Though these latter have not been hitherto satisfactorily accounted for, one remarkable fact has been observed in relation to them, namely, that when the energy by which the organisms move in a given direction is exhausted they forthwith pursue an opposite course, and this intermittency is continued indefinitely. Thus the normal movement of a Diatom, a Navicula, for example, is either zig-zag or backwards and forwards on the 
same line, as we shall presently see. But the kind of movement unquestionably depends upon the shape of the frustule, a fact which does not appear to be recognised by writers, who deal with the subject in a general way. Thus, if the form is elongated or boat-shaped, as in Navicula, the movement will be in the line of the longitudinal axis, but if the form is short or irregular a wabbling movement will be observed. The movement of a true Bacterium is excursive, while that of a Micrococcus is a jostling dance, due to the special form and the interchange of actions in the minute parts of the protoplasm. In Flügge's great work, translated by $\mathrm{Mr}$. Watson Cheyne, page 159 , he states that "some vegetative forms and species of Bacteria are always at rest; thus the spherical cells and all those species which occur only in the form of Micrococci exhibit only a trembling movement, with very slight alteration of position, which may be referred to unavoidable agitation and currents," which latter remark appears to show that he did not apprehend the true cause of the movement itself or of its peculiar character. Indeed, on page 558 he remarks that "The movements of Fission Fungi are swimming movements in fluid media, and are generally or always produced by cilia," a very doubtful position. But, to return, it is now well known that if Diatomaceous frustule in its onward movement meets with an obstruction, it will naturally appear to contend with the difficulty, and in clue time of course recede. Thus, the very fact which was at one time best calculated to support the volitional theory is shown to be deceptive. If we divide a frustule of Navicula into two parts by an imaginary line through its short diameter, each half will probably contain a considerable mass of endochrome and a highly refracting globule, much resembling that which we observe in the Thalassicollide, and which probably discharges a similar office. Now, to understand how movement takes place, say to the right, we have only to suppose that the right half of the frustule is taking up endosmotic currents, while exosmosis is going on in the left half. The former would, as it were, draw it to the right, while the latter would impel it in the same direction, but when these conditions are reversed the frustule will move to the left, or, in other words, the little ship will take an opposite course in the trackless field of the microscope. Bascillario executing their fantastic compound movements, and even Oscillatorians waving like cilia on a magnificent scale, fall into the same category.

When we come to study the numerous minute forms of algce, both marine and aquatic, we find either that, the individual cells or definite groups of them are enveloped in a more or less consistent gelatinous substance which acts as a dialyser or medium 
through which the materials of their nutrition are absorbed on the nine liand, and the waste or effete matters of the organism are thrown off on the other. The gelatinous envelope in many cases takes so characteristic or definite a shape as to have obtained for it the name of a frond. It is sometimes beautifully laminated or dichotomously branched, globular or simply expanded floating or encrusting. The ordinary Bacterium ter mo and its allies which are individually surrounded with gelatinous matter either free, or clustered in the Zooglax form, carry on their vital functions in a similar way; and it is incontestable that not only the matters which form their pabulum, but those effete compounds resulting from the waste of their substance, are in perfect solution in the surrounding water. Now, if we suppose only the waste materials or any part of them to be giseous, they would first be held in solution up to the point of saturation, and then overflow or pass off into the surrounding air. There is great reason to believe that the subtle principles which may be assumed to be the cause of the must serious forms of specific disease are quite inodorous. In this light the mure offensive gases have been regarded as the heralds of warning, either forbidding our approach, or demanding their own extinction, that in like manner more dangerous emanations may be either aroided altogether or divested of their power by the means employed in the tirst instance to correct a disagreeable odour.

The gelatinous coat of Bacteria and Micrococci raries much in its consistency under different circumstances and may even undergo complete solution.

It is apparently precipitated by chloride of lime, cupr:ilum and some other disinfectants, including also the Bacteria. I can not be very certain, but it seems to me to disappear under the action of carbolic acid so far as to liberate the Bacteric and give them a more equable distribution over the field of the microscope. Now, it must be remembered that although colloidal substances in a concentrated state will not dialyse, they will do so when largely diluted, just as they would commonly occur in drinking wates admitting for a moment their solubility. I mention this merely as another possible source of water contamination, that may not hitherto have been taken into account by Hygienists. 